Document downloaded from:

http://hdl.handle.net/10251/102182

This paper must be cited as:

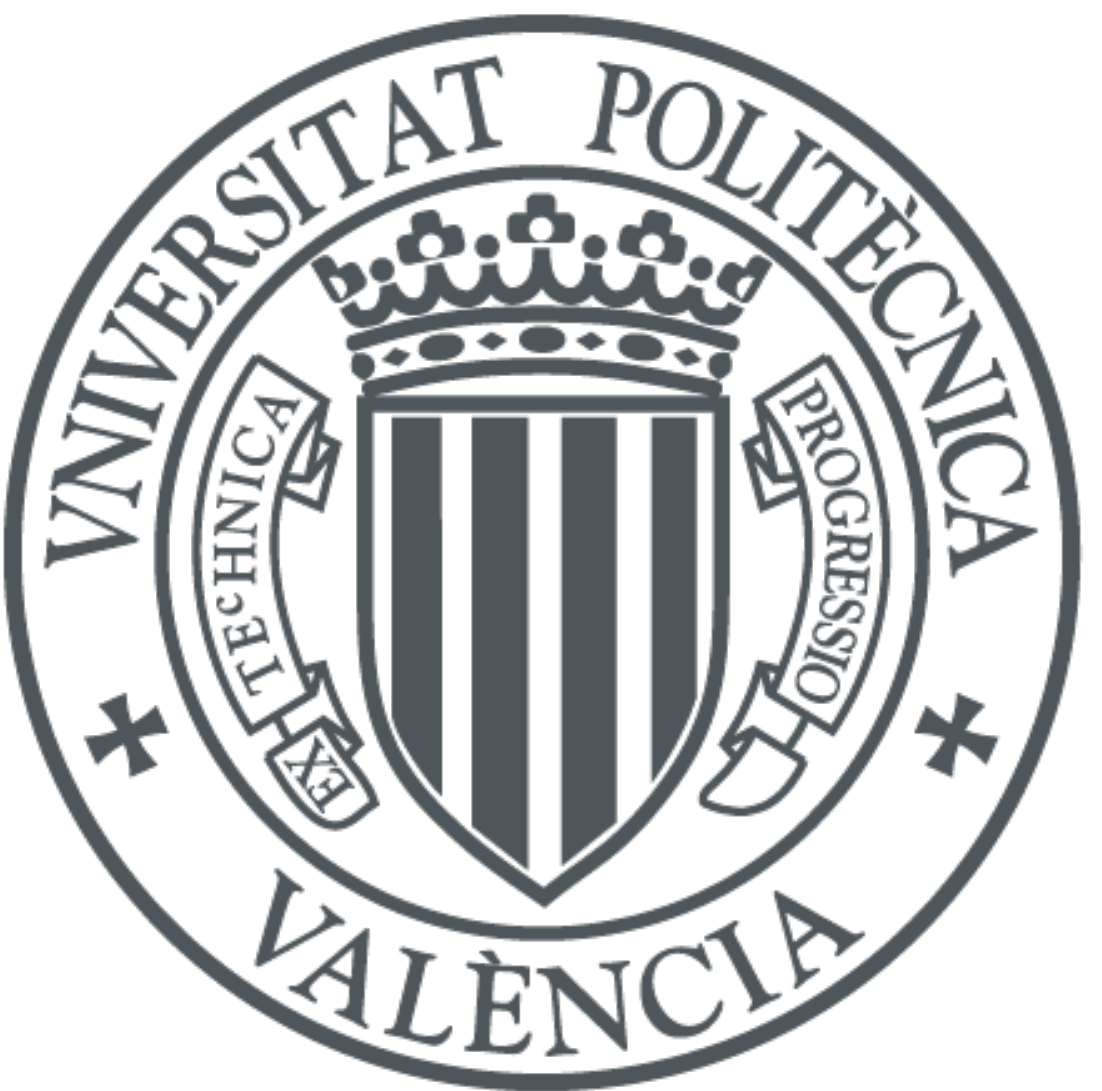

The final publication is available at

https://doi.org/10.1177/1468087416685965

Copyright SAGE Publications

Additional Information 


\title{
X-ray radiography of cavitation in a beryllium alloy nozzle
}

\author{
Daniel J. Duke ${ }^{1 *}$ Katarzyna E. Matusik ${ }^{1}$, Alan L. Kastengren ${ }^{2}$, \\ Andrew B. Swantek ${ }^{1}$, Nicholas Sovis ${ }^{1}$, Raul Payri ${ }^{3}$, \\ Juan P. Viera ${ }^{3}$ and Christopher F. Powell ${ }^{1}$ \\ ${ }^{1}$ Energy Systems Division, Argonne National Laboratory, Lemont Illinois 60439 USA \\ ${ }^{2}$ X-ray Science Division, Argonne National Laboratory, Lemont Illinois 60439 USA \\ ${ }^{3}$ CMT-Motores Térmicos, Universitat Politècnica de València, Camino de Vera s/n, \\ 46022 Valencia, Spain
}

\begin{abstract}
Making quantitative measurements of the vapor distribution in a cavitating nozzle is difficult, owing to the strong scattering of visible light at gas-liquid boundaries and wall boundaries, and the small length and time scales involved. The transparent models required for optical experiments are also limited in terms of maximum pressure and operating life. Over the past few years, $\mathrm{x}$ ray radiography experiments at Argonne's Advanced Photon Source have demonstrated the ability to perform quantitative measurements of the line of sight projected vapor fraction in submerged, cavitating plastic nozzles. In this paper, we present the results of new radiography experiments performed on a submerged beryllium nozzle 520 microns in diameter, with a length/diameter ratio of 6 . Beryllium is a light, hard metal that is very transparent to x-rays due to its low atomic number. We present quantitative measurements of cavitation vapor distribution conducted over a range of non- dimensional cavitation and Reynolds numbers, up to values typical of gasoline and diesel fuel injectors. A novel aspect of this work is the ability to quantitatively measure the area contraction along the nozzle with high spatial resolution. Analysis of the vapor distribution, area contraction and discharge coefficients are made between the beryllium nozzle, and plastic nozzles of the same nominal geometry. When gas is dissolved in the fuel, the vapor distribution can be quite different from that found in plastic nozzles of the same dimensions, although the discharge coefficients are unaffected. In the beryllium nozzle, there were substantially fewer machining defects to act as nucleation sites for the precipitation of bubbles from dissolved gases in the fuel, and as such its effect on the vapor distribution was greatly reduced.

keywords: Cavitation, x-ray, radiography
\end{abstract}

\section{Introduction}

Cavitation has a strong impact on the flow structures inside high pressure fuel injection nozzles, and its effects on both nozzle wear and spray structure have been studied for some time $[1,2,3,4]$. The changes in atomization triggered by cavitation are known to influence engine emissions [5]. However, the physics of cavitation in highly turbulent flow are not yet fully understood [6]. Substantial effort continues to be made in the development of numerical models for cavitating nozzle flows $[7,8,9,10,11]$. These efforts require experimental validation with quantitative data that has both the spatial and temporal resolution to match the simulations.

Cavitation is difficult to measure inside fuel injectors, as the multiple gas-liquid interfaces scatter visible light strongly and refractive index matching is not always possible. At a minimum, optical techniques require the manufacture of transparent injector tips. While many experiments on transparent injectors have used scaled-up models, recent developments have demonstrated the ability to make optical measurements at real scale $[12,13,14]$. However, transparent models are limited by several factors. Acrylic or polycarbonate plastic nozzles with realistic geometries are generally limited to low operating pressures relative to steel nozzles, due to both internal stresses and the strength of the attachment to the injector body. High-pressure designs require simplification of the geometry $[15,16]$. They also have a short operating lifetime, and generally cannot be used under combustion conditions. Finally, the surface

*Corresponding author: dduke@anl.gov 
roughness in plastic, sapphire and glass models can be very different from that of metal nozzles, although hydro-erosion processes can be used to control this to a limited extent. For the purposes of studying in-nozzle cavitation, hydro-erosion is generally not used as a sharp hole inlet edge is desired.

Visible light imaging techniques are prevalent and provide rich detail on the morphology of the flow $[17,14]$ but cannot provide direct quantitative measurements of the vapor fraction. In prior work, we have shown that complementary x-ray radiography and fluorescence techniques can be used to make quantitative measurements of the fluid density inside a cavitating nozzle [18, 19, 20, 21]. X-ray radiography has also been demonstrated in scaled up models of cavitation nozzles using medical CT devices [22] and most recently Mitroglou et al [23] have demonstrated the application of cone-beam x-ray CT to enlarged models of diesel spray nozzles, and were able to reconstruct the three dimensional vapor distribution. By focusing a monochromatic high flux x-ray beam from a synchrotron source, spatial resolution on the order of $5 \mu \mathrm{m}$ and sub-microsecond temporal resolution is possible [24].

In our prior work, plastic nozzles were used [18]. Although x-rays do not require optically transparent materials, the transmission of x-rays through a steel nozzle at the wavelengths which provide good contrast in hydrocarbon fuels is effectively zero. In Figure 1, calculations of the radiography contrast of $0.1 \mathrm{~mm}$ of decane doped with a cerium contrast agent are shown, through a $0.1 \mathrm{~mm}$-thick nozzle wall made of various materials, with allowance for a $2 \mathrm{~cm}$ air gap [25]. Here, the contrast is defined in arbitrary units as

$$
c=\sqrt{\tau_{\text {total }}}\left(1-\tau_{\text {fluid }}\right)
$$

where $\tau_{\text {total }}$ is the non-dimensional x-ray transmission through the nozzle and $1-\tau_{\text {fluid }}$ is the absorption in the fluid, which is the quantity we wish to measure. In Figure 1, $100 \mu \mathrm{m}$ of decane has been used as a reference to estimate $c$. Polymer nozzles have an absorption profile similar to the fuel and are more suitable for radiography (Fig. 1). However, the limits of low operating pressure and unrealistic wall roughness still apply. Plastics are also damaged due to the heat load from the incident x-ray beam, and this shortens their operating life. Recent optical experiments using sapphire nozzles have shown promise for high pressure optical imaging (Falgout et al, 2015) but these are unsuitable for x-ray experiments.

Prior x-ray measurements of cavitation in steel nozzles [26] have been limited to phase-contrast imaging at higher x-ray energies (above $25 \mathrm{keV}$ ). In order to perform radiography at lower energies, we can instead machine nozzles from beryllium $(Z=4)$. To a rough approximation, photoelectric absorption increases with the 4 th power of the atomic number and decreases with the $3 \mathrm{rd}$ power of the $\mathrm{x}$-ray energy [27]. Low-Z metals are therefore virtually transparent to $\mathrm{x}$-rays at the relevant energies for radiography in hydrocarbon fuels, even though they are opaque to visible light (Fig. 1). In this study, we have machined a test nozzle from S200 beryllium alloy. Beryllium is commonly used to manufacture x-ray windows, and has been used in the past to make x-ray transparent spray nozzles [28]. It can withstand relatively high stresses compared to plastics. The oxide layer that forms on contact with air is stable and does not impede x-ray transmission. However, beryllium is brittle and the dust produced during machining is toxic, entailing high cost.

In this paper, we present x-ray radiography experiments conducted in a beryllium nozzle under submerged conditions (i.e. injecting into fluid rather than gas). Cavitation is quantitatively measured in the nozzle by comparing the change in line of sight projected density and vapor volume fraction between cavitating and non-cavitating conditions at cavitation and Reynolds numbers spanning a wide range, up to those found in gasoline and diesel direct injection systems. We present a comparison of the time average vapor distribution in the beryllium nozzle to previous measurements in plastic nozzles made from various materials of similar dimensions under the same operating conditions.

A novel aspect of the work is that the quantitative vapor fraction measurements can be integrated to calculate physical area contraction coefficients. Comparison of experiments with degassed and untreated calibration fluids indicate that the reduction of nucleation sites in the metal nozzle causes a marked difference in the effect of non-condensable gas relative to plastic nozzles, but the presence of dissolved gas does not substantially alter the discharge coefficient.

In order to simplify the fluid dynamics, the nozzle geometry and incoming flow conditions are axisymmetric and non-swirling. The nozzle diameter has been slightly enlarged to facilitate high-resolution measurements and achieve injection-relevant Reynolds and cavitation numbers at lower pressures. In the axisymmetric case, film-type cavitation at the nozzle walls is dominant, and the cavitation vapor is relatively steady, making time-average measurements feasible [18]. In realistic injector geometries, asymmetries in the flow and complexity in the geometry introduce additional phenomena such as string cavitation and asymmetric cavity growth [29]. Furthermore, the large length to diameter ratios of diesel 


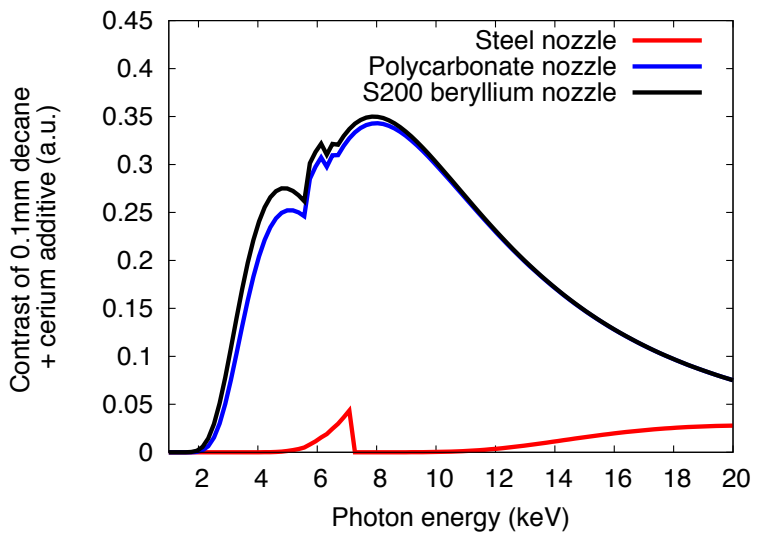

Figure 1: Radiography contrast (arbitrary units) of $0.1 \mathrm{~mm}$ of decane with cerium contrast agent (9:1 $\mathrm{v} / \mathrm{v}$ ) in an $0.1 \mathrm{~mm}$ thick geometry made of several materials, vs. x-ray energy.

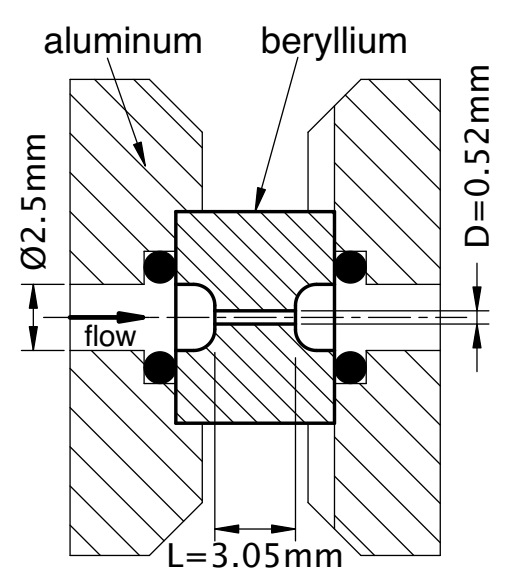

(a) Nominal geometry of beryllium nozzle and aluminum clamps.

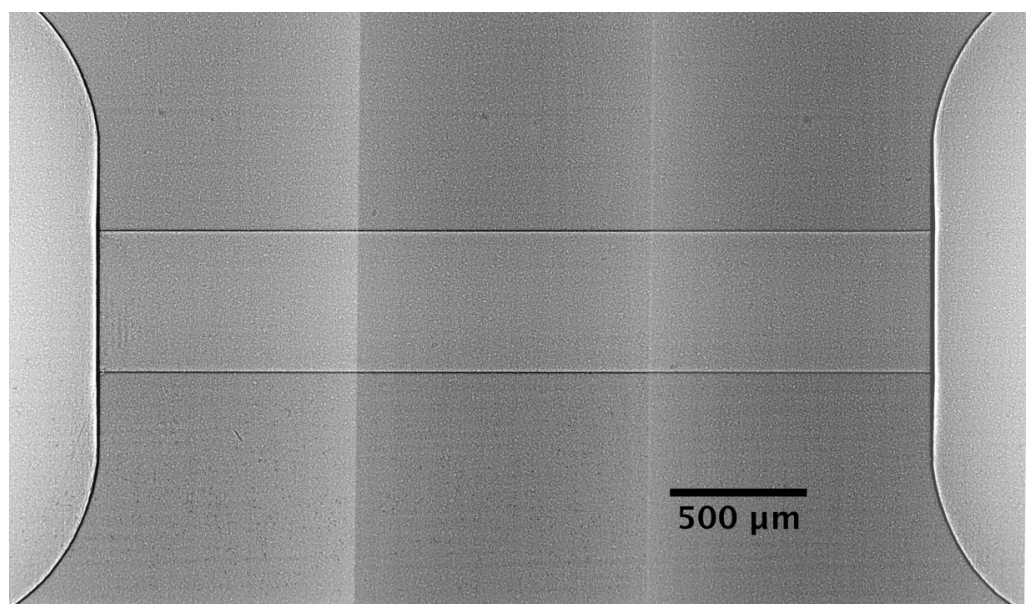

(b) Actual geometry, measured using static full field x-ray imaging at $1.17 \mu \mathrm{m}$ per pixel resolution.

Figure 2: Geometry of beryllium nozzle.

nozzles and the short length to diameter ratios of gasoline nozzles produce very different flow characteristics due to the effects of nonlinear phenomena such as supercavitation and hydraulic flip[30]. In addition to serving as a proof of concept, the purpose of these experiments is to aid in understanding how the development of the geometric cavitation film in a round nozzle changes with Reynolds and cavitation number under well-controlled boundary conditions. This understanding will improve the predictive capability of models which can be used to study nozzle cavitation under realistic engine conditions. The ability to quantitatively measure the liquid-vapor distribution will benefit to the study of gasoline direct injection sprays in particular, as the small length to diameter ratio of the holes in these injectors make the nozzle exit conditions sensitive to the vena contracta profile[31].

\section{Method and materials}

The experiments were carried out in a nozzle made from S200 grade beryllium, machined with a diameter of $\mathrm{D}=0.52 \mathrm{~mm}$ and length $\mathrm{L}=3.05 \mathrm{~mm}$, with an expansion/contraction ratio of 5 , as shown in Figure 2a. The beryllium insert was compressed between two aluminum clamps sealed with O-rings. Fluid flowed from top to bottom through a long straight inlet section with a fine mesh screen placed several $\mathrm{cm}$ upstream of the nozzle inlet. The true geometry of the nozzle was measured using static full field x-ray imaging at a resolution of $1.17 \mu \mathrm{m} /$ pixel as per Fig. $2 \mathrm{~b}$, which confirms the absence of any large-scale $(>2 \mu \mathrm{m})$ geometric defects. The fluid was supplied from a piston accumulator charged with regulated 
Table 1: Conditions for x-ray experiments, as compared to nominal conditions for GDI and diesel injectors.

\begin{tabular}{|c|c|c|c|c|c|c|c|}
\hline Variable & $\begin{array}{l}\text { Condition } \\
\text { A }\end{array}$ & $\begin{array}{l}\text { Nominal } \\
\text { Diesel }\end{array}$ & $\begin{array}{l}\text { Condition } \\
\text { B }\end{array}$ & $\begin{array}{l}\text { Nominal } \\
\text { GDI }\end{array}$ & $\begin{array}{l}\text { Condition } \\
\text { C }\end{array}$ & $\begin{array}{l}\text { Condition } \\
\text { sweep D }\end{array}$ & $\begin{array}{l}\text { Condition } \\
\text { sweep E }\end{array}$ \\
\hline Nozzle diameter $(\mu \mathrm{m})$ & 500 & 180 & 500 & 200 & 500 & 500 & 500 \\
\hline $\begin{array}{r}\text { Inlet Pressure } P_{1} \\
\text { (bar abs.) }\end{array}$ & 23.7 & 1500 & 27.6 & 200 & 10 & $2.4-2.5$ & $2.5-25$ \\
\hline $\begin{array}{r}\text { Back Pressure } P_{2} \\
\text { (bar abs.) }\end{array}$ & 0.31 & 20 & 0.80 & 6 & 1 & $0.24-0.8$ & $0.24-2.5$ \\
\hline Reynolds Number $\operatorname{Re}_{D}$ & $2.4 \times 10^{4}$ & $2.4 \times 10^{4}$ & $2.5 \times 10^{4}$ & $2.5 \times 10^{4}$ & $1.5 \times 10^{4}$ & $7 \times 10^{3}$ & $\begin{array}{l}7 \times 10^{3} \\
-3.5 \times 10^{4}\end{array}$ \\
\hline Cavitation Number $K$ & 1.01 & 1.01 & 1.03 & 1.03 & 1.11 & $1.10-1.57$ & 1.11 \\
\hline
\end{tabular}

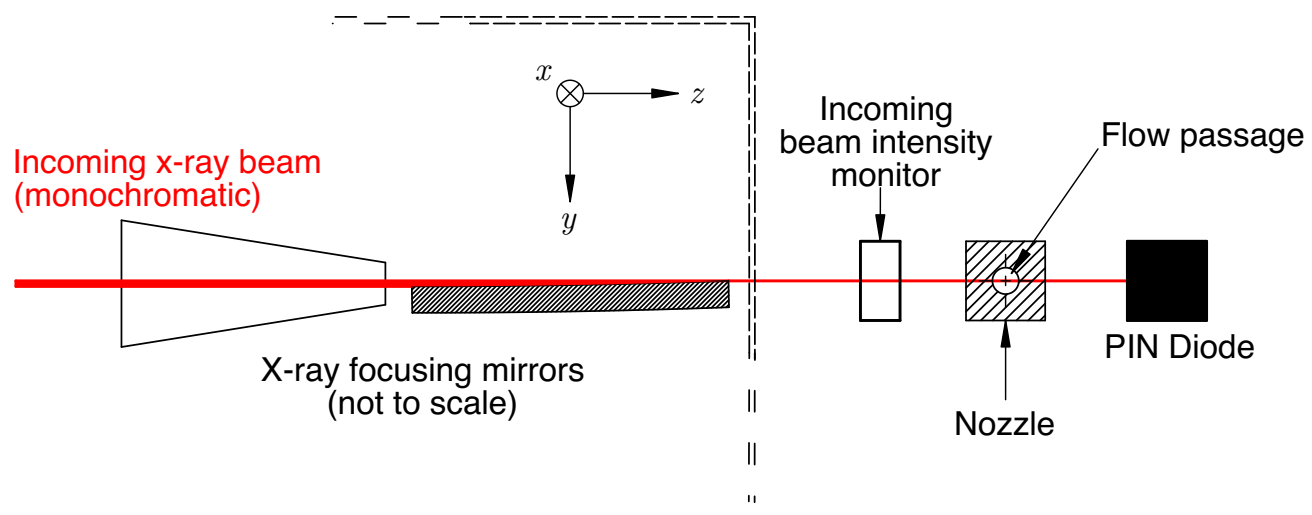

Figure 3: Experiment layout, plan view.

nitrogen, and the back pressure was maintained using a vacuum pump and needle valve on the drainage tank [32]. The inlet and outlet flow static pressures and temperatures were recorded and the flow rate was independently monitored using a turbine flowmeter.

The working fluid was a gasoline-like calibration fluid (Viscor 16br, Rock Valley Oil \& Chemical Company) with properties similar to decane, doped with a cerium additive (Eolys Rhodia DPX9) at a 9:1 volume ratio. The cerium additive acts as a contrast agent. Its effect on the viscosity and density of the fluid were measured and accounted for in the analysis. In this study, we define the cavitation number as

$$
K=\frac{P_{1}-P_{v}}{P_{1}-P_{2}}
$$

where $P_{1}$ and $P_{2}$ are the inlet and outlet pressures, and $P_{v}$ is the vapor pressure of the fluid (in this experiment, $P_{v} \approx 400 \mathrm{~Pa}$ ). Cavitation phenomena increase asymptotically in the limit $K \rightarrow 1$ and above some upper limit $K_{C}$ there is no cavitation, as per the approach of Payri et al (2013). The nozzle Reynolds number is defined as

$$
\operatorname{Re}_{D}=\frac{\bar{U} D}{\nu}=\frac{4 \dot{Q}}{\pi D \nu}
$$

where $\dot{Q}$ is the liquid volume flow rate and $\nu$ is the kinematic viscosity. In these experiments, inlet pressures up to 27 bar absolute were investigated. The beryllium nozzle is rated to 69 bar. In this experiment we chose lower injection pressures intentionally, so that the $\operatorname{Re}_{D}$ and $K$ are equivalent to that which would be expected in a diesel injector of smaller diameter but higher injection pressure. The large diameter relative to typical diesel and gasoline geometries was chosen due to machining and spatial resolution considerations. The x-ray beam focus size is about $1 \%$ of the nozzle diameter in the current configuration, giving sufficient resolution to capture small transverse variations due to asymmetry in the vapor distribution.

Since both the pressures and mass flow rate are independently measured, the nozzle discharge coef- 
ficient can be determined (Payri et al, 2009);

$$
C_{D}=\frac{4 \dot{m}}{\pi D^{2} \sqrt{2 \rho_{L} \Delta P}} .
$$

Experiments were conducted at cavitation and Reynolds numbers similar to those found in gasoline and diesel direct injection systems, as shown in Table 1. Experiments A and B were designed to match nominal diesel and GDI $\operatorname{Re}_{D}$ and $K$. Experiment $\mathrm{C}$ was designed to match prior measurements performed at lower pressures in plastic nozzles [18]. Parameter sweeps (denoted D and E) were also conducted over a range of conditions, spanning both fixed $\mathrm{Re}_{D}$ and fixed cavitation number conditions. The x-ray experiments were conducted with the fluid at $300 \mathrm{~K}$.

The experiments were performed at the 7-BM beamline of the Advanced Photon Source at Argonne National Laboratory [33]. A simplified schematic of the experiment is shown in Fig. 3. This setup is similar in design to previous radiography experiments using plastic nozzles, and further detail can be found in previously published work $[18,19,20,21]$. A monochromatic x-ray beam of mean energy 9 $\mathrm{keV}$ ( $4.2 \%$ FWHM bandpass) was focused to a $5 \mu \mathrm{m} \times 6 \mu \mathrm{m}$ spot using a pair of Kirkpatrick-Baez x-ray focusing mirrors. The beam focal spot was aligned with the mid-plane of the test geometry.

Time averaged measurements were performed using a raster-scan approach, moving the nozzle in $\mathrm{x}$ and $y$ through the fixed beam. To improve the speed of the measurements, a fly-scanning configuration was used. The nozzle was translated vertically (in the $\mathrm{x}$ axis) through the fixed beam at a steady velocity of $0.25 \mathrm{~mm} / \mathrm{s}$, and the x-ray intensity was binned and recorded every $100 \mathrm{~ms}$ to give a spatially resolved axial scan profile with a resolution of $25 \mu \mathrm{m}$. This process was repeated at multiple transverse positions in the y axis to construct a two-dimensional map of the x-ray transmission through the nozzle. The measurements were repeated from two viewing angles $\left(0^{\circ}\right.$ and $\left.90^{\circ}\right)$ by rotating the nozzle about its vertical axis, in order to capture any three-dimensional features.

The radiography measurements fundamentally measure the pathlength-integrated amount of liquid in the x-ray beam. Voids show as a displacement of the fluid compared to a reference scan of a low-speed flow (where no cavitation is expected). At each measurement location, the projected density of displaced fluid $\Delta M$ (units mass per area) is related to the measured transmission by the Lambert-Beer law;

$$
\Delta M=\int \rho d z=\frac{-1}{\mu} \log \left(\frac{I}{I_{0}} \cdot \frac{I_{0, r e f}}{I_{\text {ref }}}\right) .
$$

Here, the mass attenuation coefficient $\mu$ is determined by calibration of the working fluid under static conditions in a cuvette. In this study, $\mu=20.59 \mathrm{~cm}^{2} / \mathrm{g}$. The experiment was first performed under static conditions without cavitation (denoted Iref), with the nozzle filled with fluid, and then repeated under cavitating conditions (denoted I). Since the density of the calibration fluid (with cerium additive) at the inlet temperature $T_{1}=300 \mathrm{~K}$ is known $\left(\rho_{L}=0.8607 \mathrm{~g} / \mathrm{cm}^{3}\right)$, the projected mass can be converted to a line of sight equivalent volume fraction of vapor, which has units of length and is an effective path length of vapor in the beam:

$$
\int \alpha d z \equiv \frac{\Delta M}{\rho_{L}}
$$

The uncertainty in the projected densities and volume fractions is determined by photon shot noise, which follows a Poisson distribution, and the uncertainty in measuring the attenuation coefficient $\mu$. Given an incident flux approximately 1012 photons/sec and an integration time of $0.1 \mathrm{~s}$, the raw transmission measurement has an SNR of approximately $3 \times 10^{5}$. The contrast in the working fluid is on the order of $30 \%$, giving an uncertainty in the recorded intensity ratios (eqn. 5) of approximately 10-5 over the full dynamic range of measurement. The attenuation coefficient has a larger uncertainty $(0.8 \%)$; this is the main source of uncertainty in this study. Propagating the error through the logarithm (eqn. 5), the resulting uncertainty in $\Delta M$ is $\pm 1.9 \mu \mathrm{g} / \mathrm{mm}^{2}$, which corresponds to an uncertainty in $\int \alpha d z$ (eqn. 6) of $\pm 2.2 \mu \mathrm{m}$, or $0.42 \%$ of the nozzle diameter.

\section{Results and Discussion}

The line of sight averaged, time averaged vapor distribution in the beryllium nozzle is shown for experimental conditions A and B in Figures 4 and 5; two orthogonal views are shown with flow from left to right. The nozzle wall is indicated by the white region. No evident changes in the cavitation vapor distribution can be observed between conditions A and B, suggesting that the cavitation behavior is saturated at these low cavitation number conditions. 
International Journal of Engine Research Vol 18 (1-2), pp. 39-50

https://doi.org/10.177/1468087416685965

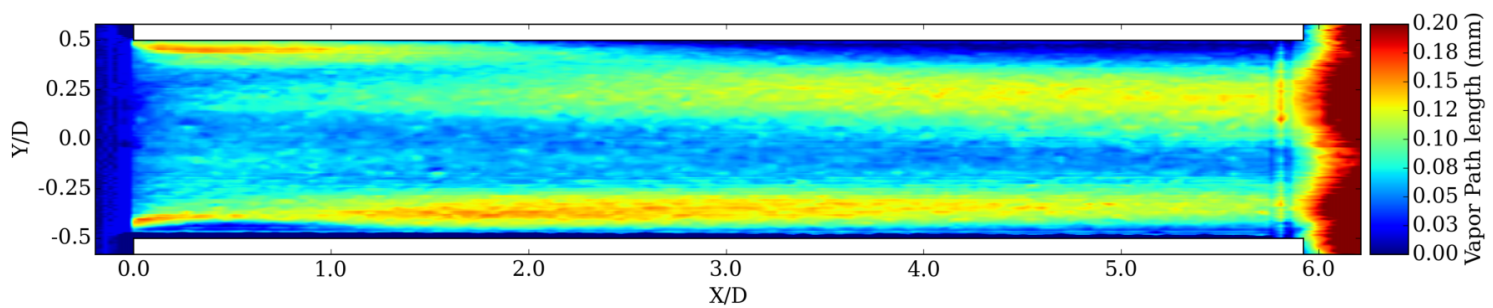

(a) Line of sight average vapor fraction at $0^{\circ}$ rotation.

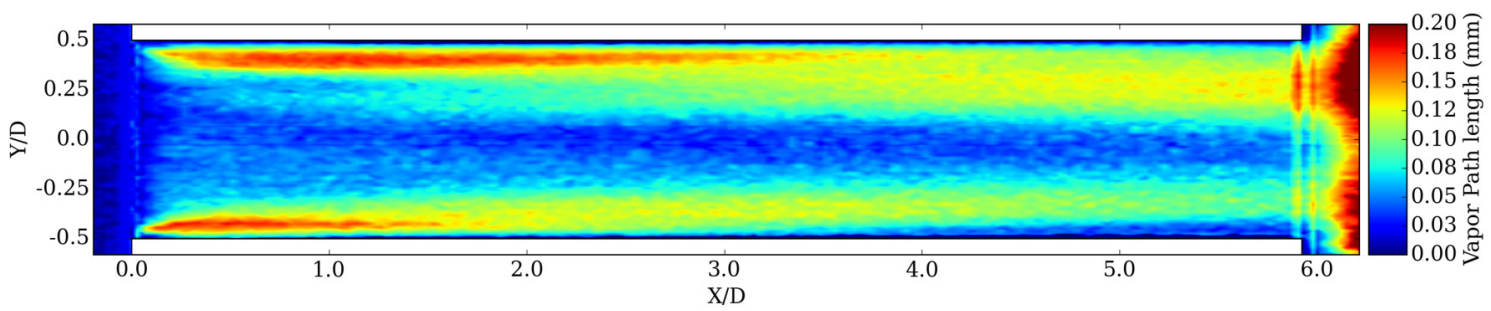

(b) Line of sight average vapor fraction at $90^{\circ}$ rotation.

Figure 4: Time average, line of sight average vapor fraction distribution in beryllium nozzle for experimental condition $\mathrm{A}\left(\operatorname{Re}_{D}=2.4 \times 10^{4}, K=1.01\right)$. Flow is left to right.

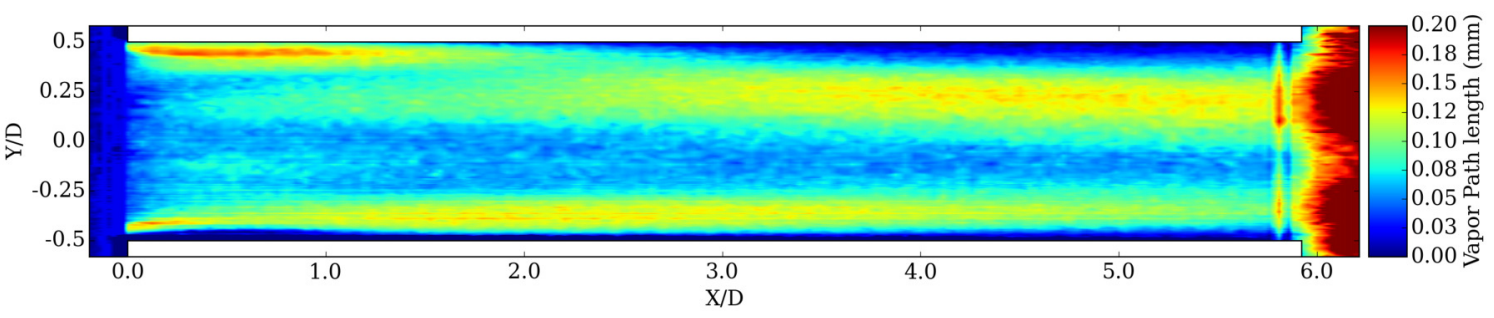

(a) Line of sight average vapor fraction at $0^{\circ}$ rotation.

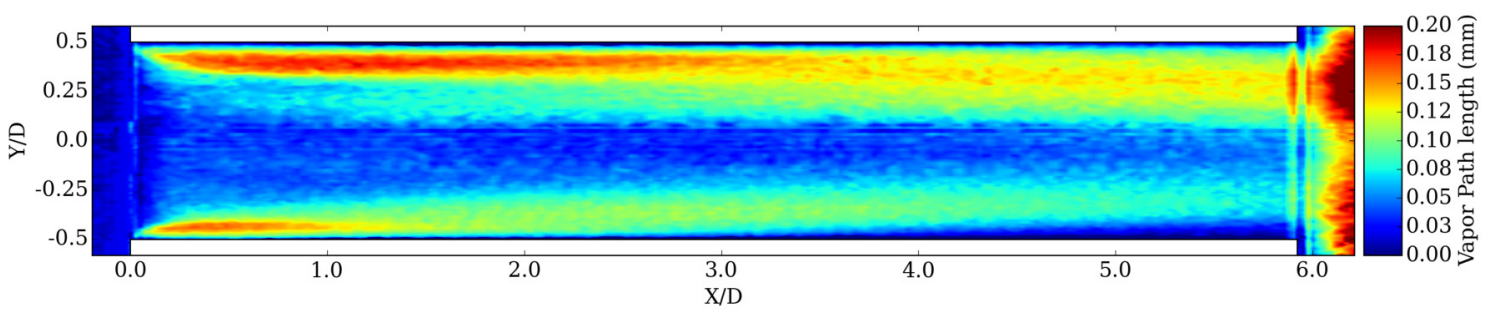

(b) Line of sight average vapor fraction at $90^{\circ}$ rotation.

Figure 5: Time average, line of sight average vapor fraction distribution in beryllium nozzle for experimental condition $\mathrm{B}\left(\mathrm{Re}_{D}=2.5 \times 10^{4}, K=1.03\right)$. Flow is left to right. 
Slight asymmetry in the flow is evident, even though the nozzle geometry is nominally axisymmetric. Figs. 4a and 5a suggest that flow separation is occurring on the upper wall; the mean vapor moves away from the wall half way down the nozzle throat, but only in the 0 view. A separation and reattachment of the vapor is also evident in Figs. 4a and 5 a near the inlet $(x / D=0$ to 1$)$ on the lower wall $(y / D=-0.5)$. This may be due to micro-scale imperfections in the nozzle wall geometry, since no large scale deviations from the nominal geometry (i.e. $>2 \mu \mathrm{m}$ ) are evident (see Figure 2b). Preliminary model fitting to the data in Figs. 4-5 suggests that the integrated vapor path lengths match the projections that would be expected if the vapor distribution was an asymmetric annulus near to the wall, with very little vapor in the center of the nozzle. The vapor path length values measured along the centerline can be explained by summation of the vapor on the front and back walls. A more detailed investigation of the threedimensional structure of the flow will be a matter for future work, and is outside the scope of this paper.

Figure 6 shows a set of measurements which sweep a range of cavitation numbers at a fixed Reynolds number $\operatorname{Re}_{D}=7000$ (Condition D, Table 1). At the critical cavitation number $K_{C} \approx 1.57$ (Fig. 6a), incipient cavitation is observed at the nozzle lip (far left, top and bottom of image). The projection suggests that a relatively axisymmetric ring of vapor is present around the nozzle inlet, with a length of approximately $100 \mu \mathrm{m}$. The bright vertical stripes at the inlet and outlet of the nozzle are artifacts caused by refraction of the x-ray beam at the inlet and outlet plenum faces, and do not necessarily indicate the presence of vapor. In Figure $6 \mathrm{~b}$, we see that a very small change in cavitation number (due to a 50 mbar reduction in back pressure) causes vapor to rapidly expand along the nozzle. The sensitivity of the flow to pressure at the critical cavitation number is such that it was not possible to find a stable operating condition between Fig. 6a and Fig. 6b. All the measurements shown in this paper were approached with a slow increase of $\mathrm{P} 1$ at fixed $\mathrm{P} 2$ in order to eliminate changes due to hysteresis. For $K$ below the critical point, the vapor distribution remains relatively similar (Figs. 6c-e). The vapor collapse location moved slightly downstream and the vapor distribution was lengthened slightly in the axial direction with decreasing $K$, suggesting a more gradual pressure recovery, but the effect was weak and the flow reached a saturated condition at $K=1.1$. For more extreme cavitation conditions $(K<1.1)$, no further changes in the vapor distribution were observed. Time-resolved measurements of these flows at several conditions suggest that the regions of moderate time-average vapor fraction moving away from the walls near the nozzle outlet are due to strong fluctuations in the distribution of the cavitation vapor [34]. This is a matter of ongoing investigation.

Figure 7 shows a set of conditions which sweep a range of Reynolds numbers at a fixed $\mathrm{K}=1.1$ (Condition E, Table 1). Much less change was observed in the vapor distribution between $\operatorname{Re}_{D}=7000$ and 35000 compared to the effect of varying the cavitation number; this agrees with the known effects of $\operatorname{Re}_{D}$ and $K$ on discharge coefficient, which are well documented [35]. A slight thinning of the attached vapor near the walls was observed at the inlet with increasing $\operatorname{Re}_{D}$. An increase in the transverse distribution of vapor in the nozzle exit region was observed with increasing $\operatorname{Re}_{D}$, although the maximum path lengths remained relatively constant. This is counter-intuitive, since it implies that the area fraction of the nozzle occluded by is increasing as the flow rate is also increasing, requiring that the fluid velocity in the exit region increase. The effect of flow area contraction will be discussed further below.

Tests were also carried out to investigate the effects of dissolved gas, since previous experiments in plastic nozzles have shown that this can significantly alter the vapor distribution [36]. In Figure 8, we compare the vapor distribution when the fuel contains dissolved $\mathrm{N}_{2}$ (Fig. 8a), and under degassed conditions (Fig. 8b). These experiments were conducted at experimental condition C (10 bar inlet pressure, 1 bar back pressure, as per Table 1) in order to match the experiments in plastic nozzles. Using the known properties of the fuel and the hydrocarbon Ostwald solubility coefficients from [37], the dissolved mass fraction of $\mathrm{N}_{2}$ is approximately $3 \times 10^{-4}$ at 1 bar. In the degassed case, the fuel was stored under vacuum for an extended period of time; the dissolved mass fraction in Fig. $8 \mathrm{~b}$ is estimated at $O\left(10^{-5}\right)$. Very little difference was observed between the experiments of Fig. 8a \& 8b. This stands in stark contrast to similar data previously collected in a polycarbonate nozzle of the same dimensions (shown in Figure 9). Here, the effect of degassing the fuel substantially reduces the amount of vapor measured inside the nozzle.

Our proposed explanation for the change in behavior between the beryllium and plastic nozzles (Figs. 9a and $9 \mathrm{~b}$ ) under dissolved $\mathrm{N}_{2}$ conditions is the relative lack of nucleation sites in the beryllium nozzle, compared to the polycarbonate nozzle. X-ray phase contrast imaging of the polycarbonate nozzles in prior work (Duke et al, 2015a) revealed a number of micro-cracks and pits in the nozzle wall due to machining defects, where a substantial amount of dissolved gas can nucleate. The migration of gas bubbles over time caused long-timescale oscillations in the structure of the attached vapor bubble. In 


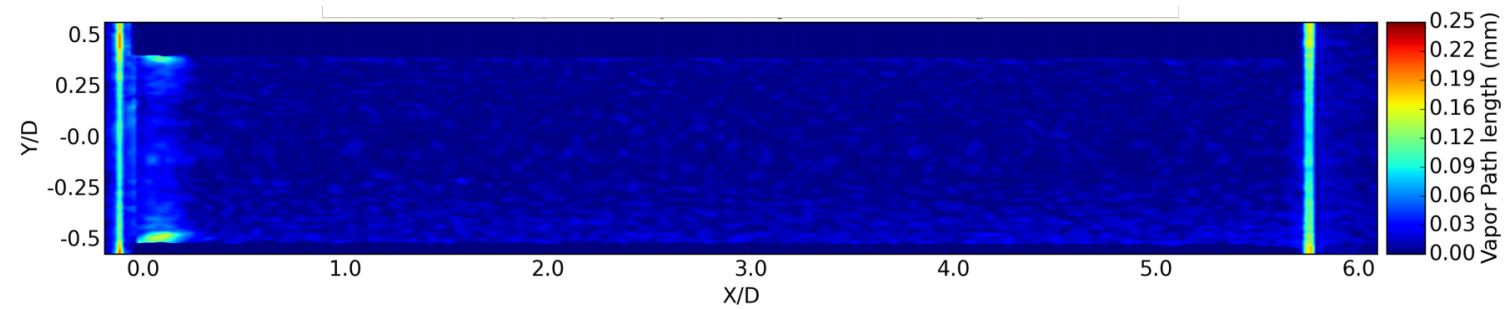

(a) $K=1.57, \operatorname{Re}_{D}=7000, P_{1}=2.4$ bar, $P_{2}=0.90$ bar.

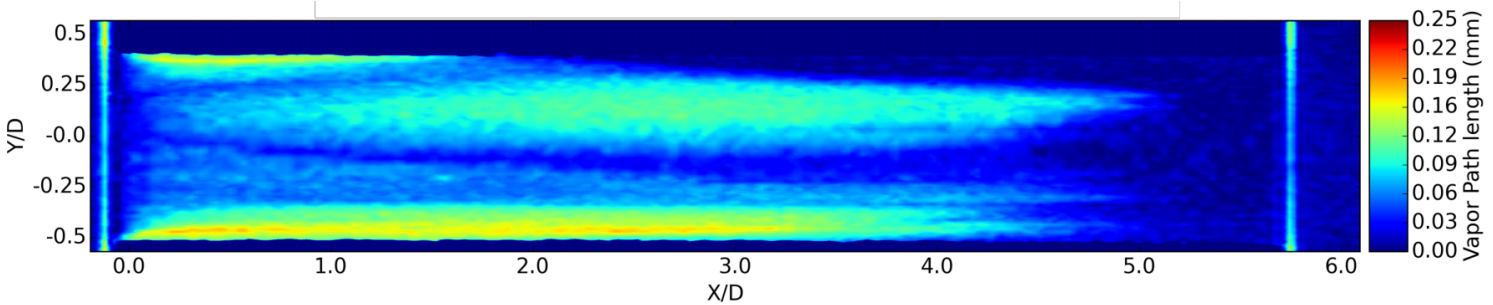

(b) $K=1.55, \operatorname{Re}_{D}=7000, P_{1}=2.4$ bar, $P_{2}=0.85$ bar.

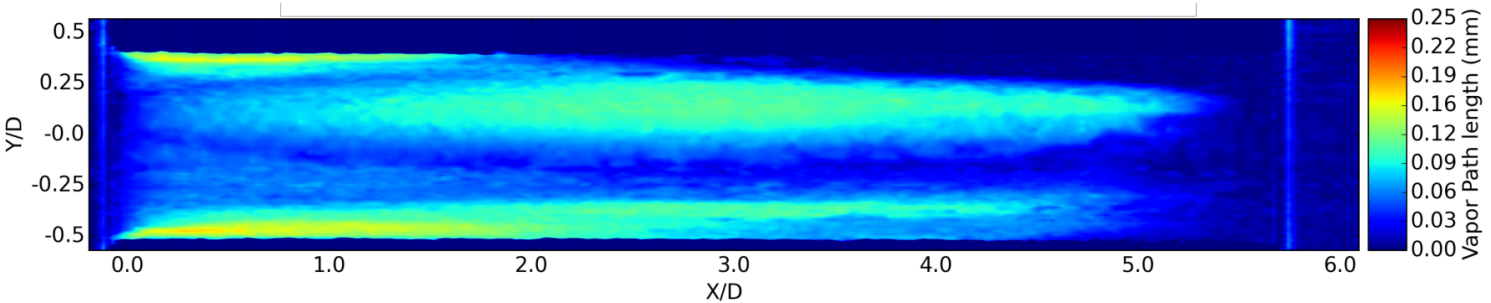

(c) $K=1.41, \operatorname{Re}_{D}=7000, P_{1}=2.4$ bar, $P_{2}=0.70$ bar.

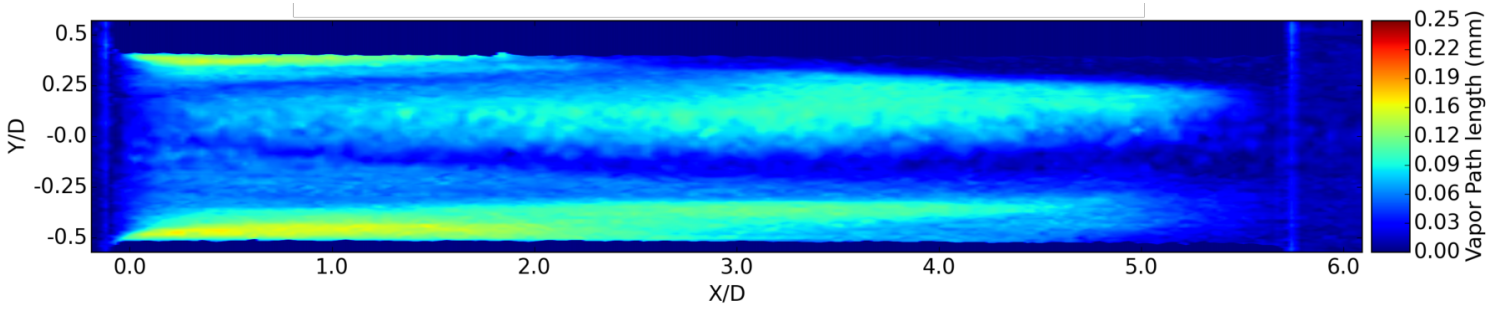

(d) $K=1.26, \operatorname{Re}_{D}=7000, P_{1}=2.5$ bar, $P_{2}=0.50$ bar.

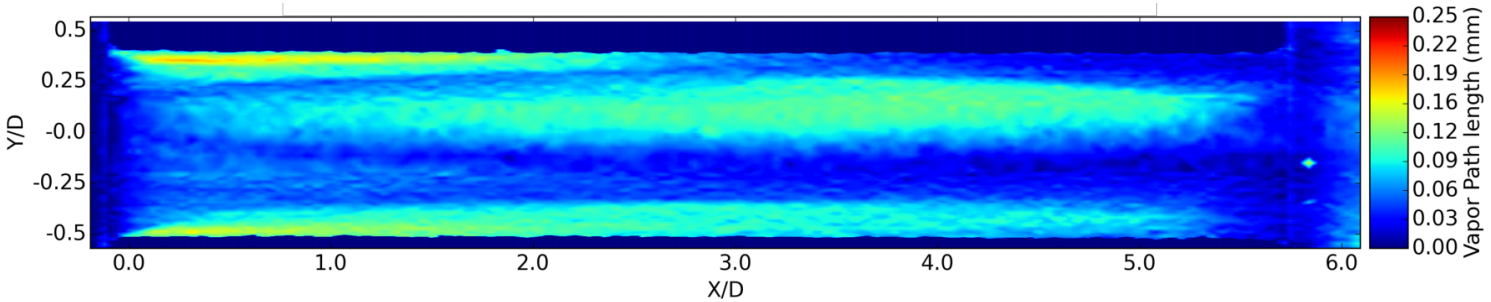

(e) $K=1.10, \operatorname{Re}_{D}=7000, P_{1}=2.5$ bar, $P_{2}=0.24$ bar.

Figure 6: Measurements at a fixed Reynolds number $\operatorname{Re}_{D}=7000$ (condition D, Table 1) for decreasing cavitation numbers from (a) incipient to (e) saturated conditions. 
International Journal of Engine Research Vol 18 (1-2), pp. 39-50

https://doi.org/10.177/1468087416685965

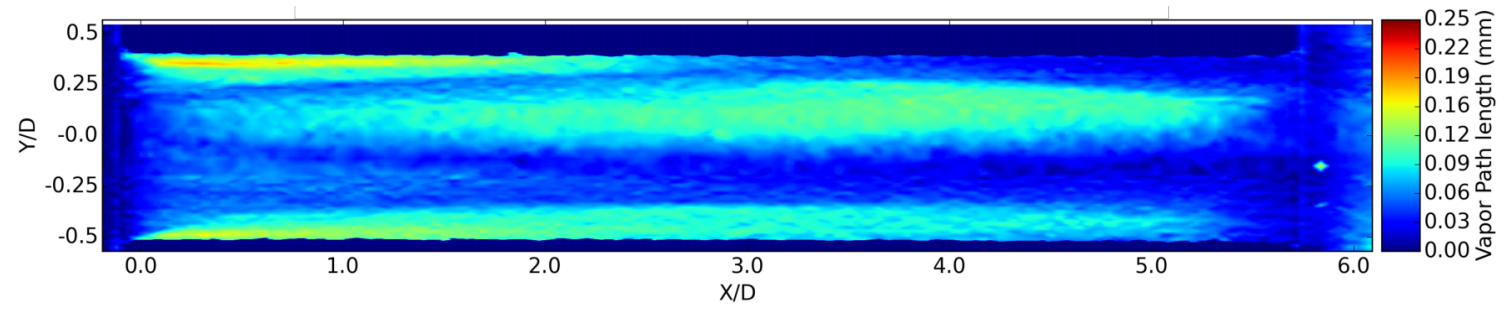

(a) $K=1.11, \operatorname{Re}_{D}=7.0 \times 10^{3}, P_{1}=2.5 \mathrm{bar}, P_{2}=0.25$ bar

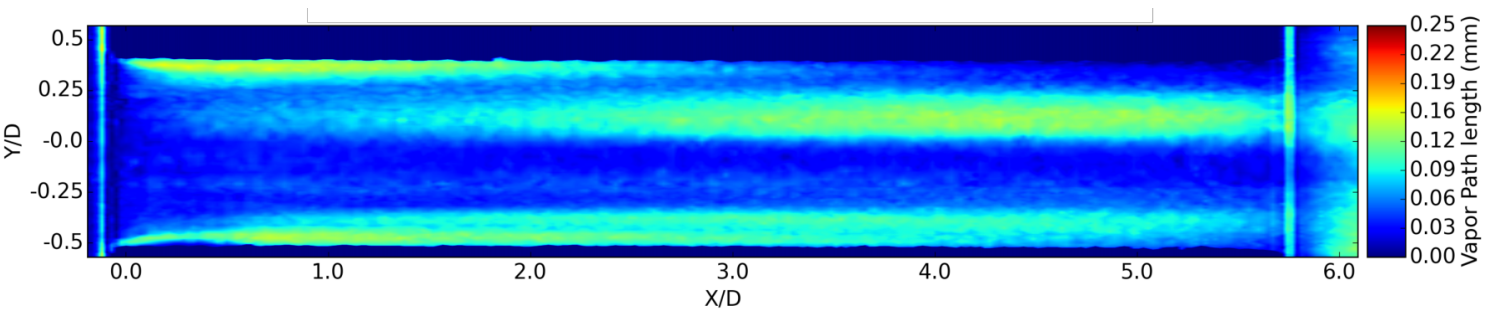

(b) $K=1.11, \operatorname{Re}_{D}=1.4 \times 10^{4}, P_{1}=10.0$ bar, $P_{2}=1.00$ bar.

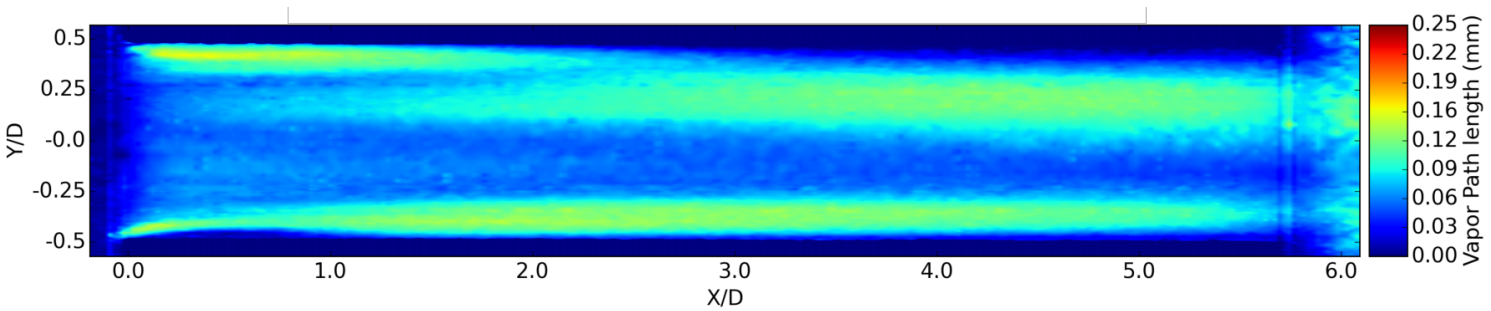

(c) $K=1.11, \operatorname{Re}_{D}=2.8 \times 10^{4}, P_{1}=19.0$ bar, $P_{2}=1.90$ bar.

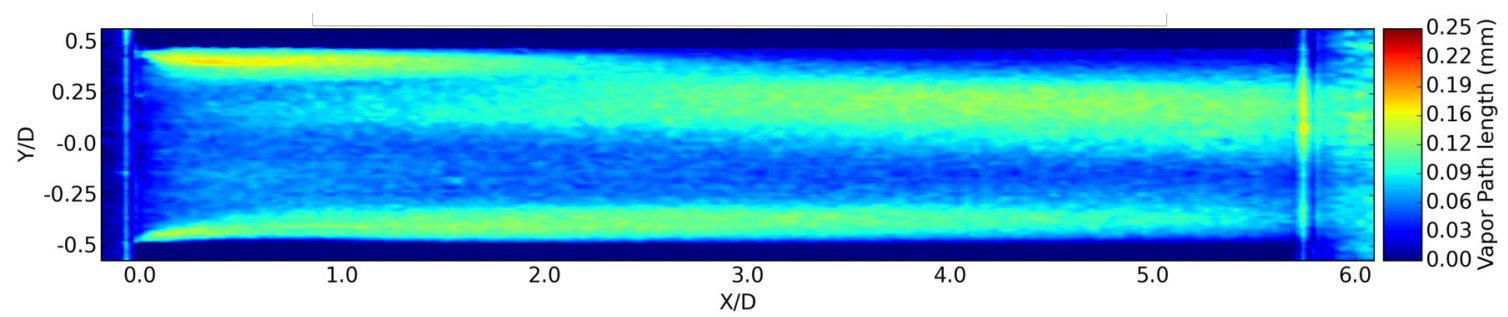

(d) $K=1.11, \operatorname{Re}_{D}=3.5 \times 10^{4}, P_{1}=25.0$ bar, $P_{2}=2.50$ bar.

Figure 7: Measurements at fixed cavitation number $K=1.11$ (condition E, Table 1) for a range of $\operatorname{Re}_{D}$. 


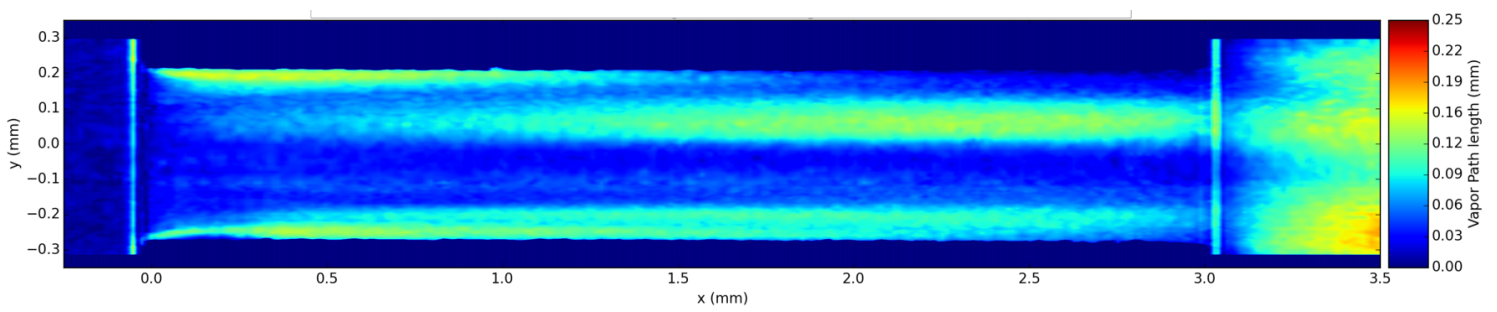

(a) Line of sight integrated vapor fraction with dissolved $\mathrm{N}_{2}$ at 1 bar equilibrium conditions.

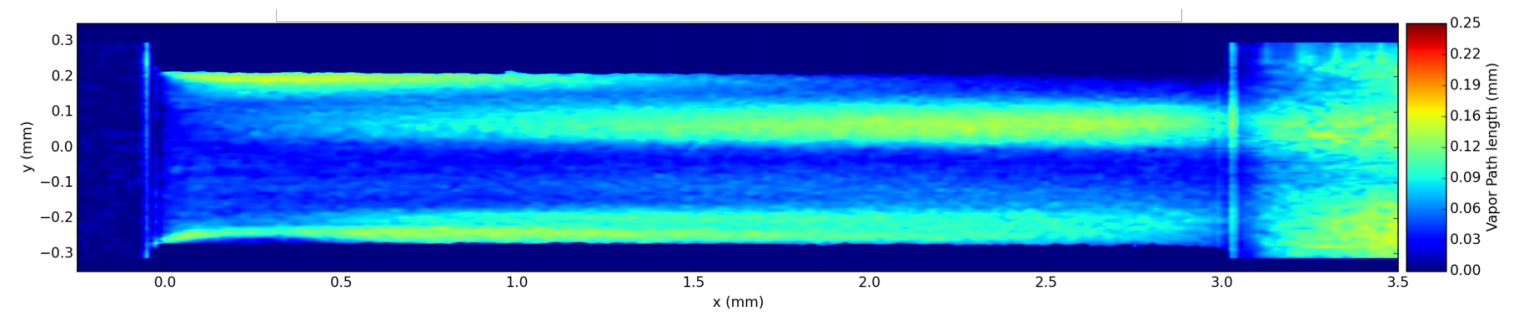

(b) Line of sight integrated vapor fraction with degassed fuel.

Figure 8: Comparison of (a) gassed and (b) degassed fuel for experimental condition $\mathrm{C}$ in beryllium nozzle (10 bar inlet pressure, 1 bar back pressure) at $0^{\circ}$ rotation view.

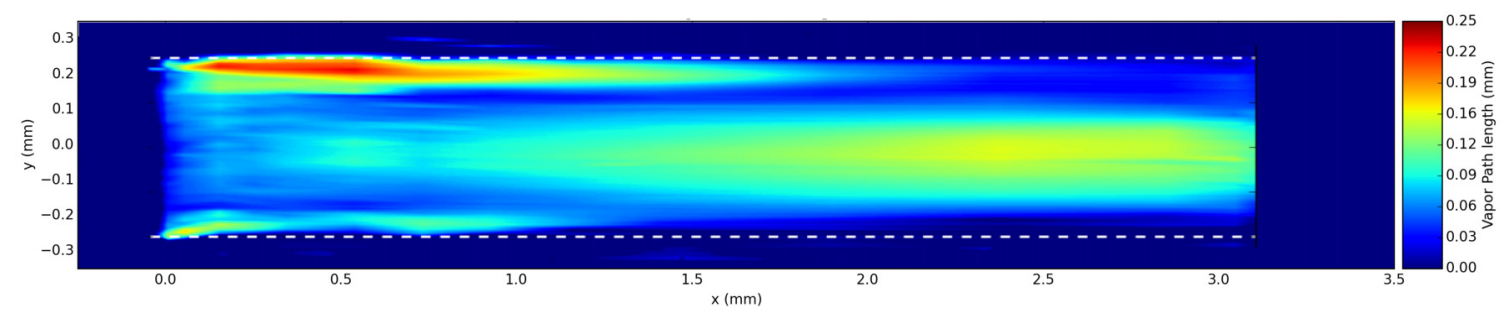

(a) Line of sight integrated vapor fraction with dissolved $\mathrm{N}_{2}$ at 1 bar equilibrium conditions.

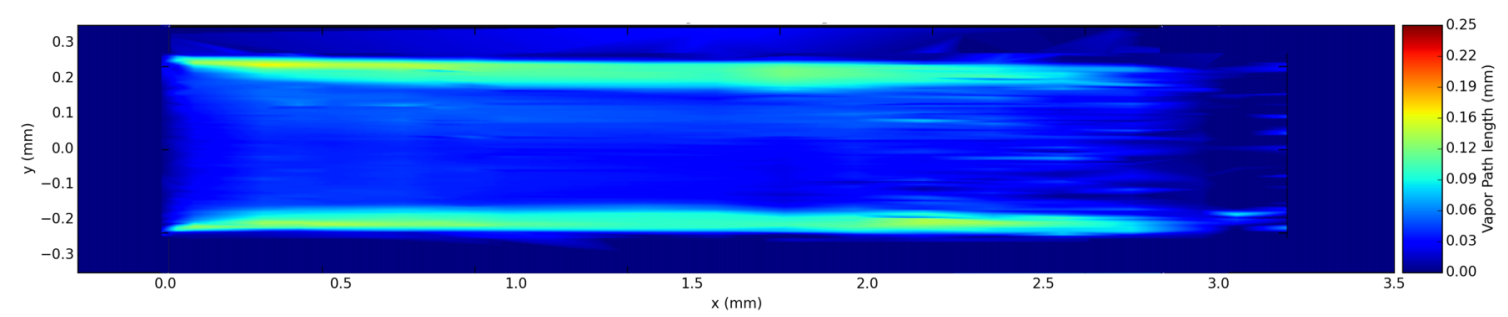

(b) Line of sight integrated vapor fraction with degassed fuel.

Figure 9: Comparison of (a) gassed and (b) degassed fuel for experimental condition C in polycarbonate plastic nozzle (10 bar inlet pressure, 1 bar back pressure) at $0^{\circ}$ rotation view. Reprinted from Atomization and Sprays vol. 23(9), Duke, D. J., Kastengren, A. L., et al, "X-ray Radiography Measurements of Cavitating Nozzle Flow", pp. 841-860, Copyright 2013, with permission from Begell House, Inc. 
International Journal of Engine Research Vol 18 (1-2), pp. 39-50 https://doi.org/10.177/1468087416685965

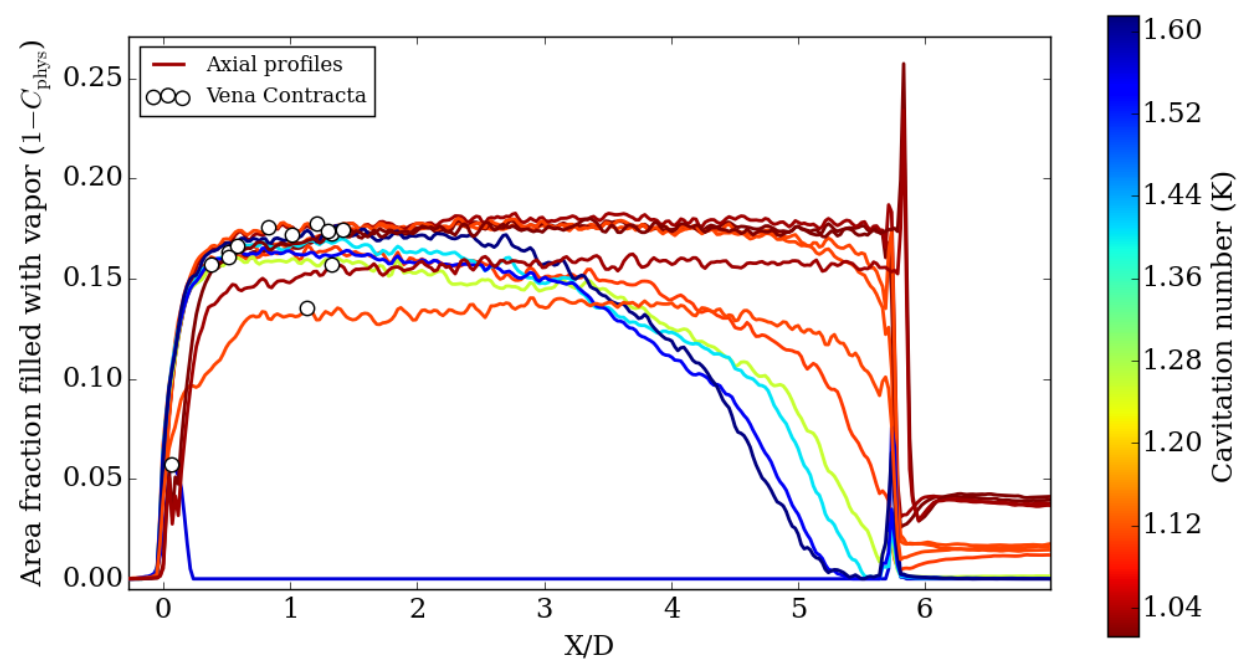

Figure 10: Axial profiles of the fraction of the hole cross-section filled with vapor $\left(1-C_{\text {phys }}\right.$, eqn. 7$)$ for the beryllium nozzle at all the conditions listed in Table 1 . The plots are colored by cavitation number. Circle markers indicate the location of the vena contracta.

the beryllium nozzle, a smoother nozzle wall with fewer and smaller crevices will reduce the opportunity for dissolved gas to come out of solution. Since the velocity of the freestream is on the order of 40 to 80 $\mathrm{m} / \mathrm{s}$ under the conditions investigated in this paper, the transit time of a fluid parcel in the nozzle is on the order of $50 \mu \mathrm{s}$. This time scale is too short to allow for the expansion of gas bubbles in the freestream at the given pressure gradient, based on our current knowledge of the behavior of non-condensable gas in cavitating nozzles $[10,36]$.

One of the advantages of the radiography measurement is that the transverse integral of the projected vapor fraction at any position along the nozzle axis quantitatively describes the cross sectional area occluded by vapor or gas. From this quantity, a physical area contraction coefficient for the liquid phase (ratio of liquid flow area to hole area) can be measured. We intuitively expect that the area contraction will change when additional dissolved gas comes out of solution. The physical area contraction coefficient is defined as a function of the axial position;

$$
\begin{aligned}
& C_{\text {phys }}(x)=\frac{A_{\text {liq. }}(x)}{A_{\text {geom. }}} \\
= & \frac{1}{A} \int(1-\alpha(x)) d A \\
= & \frac{1}{A}\left(1-\int \frac{\Delta M(x)}{\rho_{L}} d y\right)
\end{aligned}
$$

This definition of physical area contraction coefficient is distinct from the classical one-dimensional contraction coefficient $C_{c}$ [35] and the one-dimensional area coefficient [3], which correspond specifically to the estimated vena contracta and nozzle exit area. If the flow follows the one-dimensional theory, then at the vena contracta:

$$
C_{\text {phys }}\left(x_{v c}\right) \equiv C_{c} \text {. }
$$

At the nozzle exit plane, if the flow follows Desantes' model of a liquid jet surrounded by vapor, equation 7 is equivalent to the exit area coefficient;

$$
C_{\text {phys }}(L) \equiv \frac{\left(A_{\text {liq. }} \rho_{\text {avg. }}\right)}{A \rho_{L}}=C_{a} .
$$

However, the flow will not necessarily adhere to the one-dimensional model under the non-axisymmetric turbulent conditions, so we do not expect $C_{\mathrm{phys}}$ to exactly match the $C_{a}$ or $C_{c}$ predicted from onedimensional theory. 
Figure 10 shows axial profiles of the area fraction in the nozzle cross section occupied by vapor, i.e. $1-C_{\text {phys }}$, for all the conditions in Table 1. For the beryllium nozzle, the lines have been colored by cavitation number, with the weakly cavitating cases in blue and the strongly cavitating cases in red. The position of the vena contracta (minimum flow area) is indicated by the white circular markers; it falls between 0.5 and 2 diameters from the inlet. One of the most interesting features of Figure 10 is that the area fraction occupied by vapor remains relatively flat after the vena contracta. The vapor area fraction does not immediately decrease, as is typically depicted in simplified schematics of cavitating flows [38], except in the case of incipient cavitation (i.e. Fig. 6a condition). For the most strongly cavitating cases (red lines), the physical area contraction remains completely flat until the flow reaches the outlet plenum, at which point it suddenly drops due to the expansion of the diameter. In absolute terms, the area occupied by vapor remains high in the outlet plenum in these cases, indicating super-cavitation. The spike at the nozzle outlet is an artifact caused by refraction at the plenum wall and is not indicative of vapor production. Increasing $\operatorname{Re}_{D}$ also results in a flatter profile similar to the effect of decreasing $\mathrm{K}$, although its effect on the flow is much weaker and requires further investigation.

We expect $C_{\text {phys }}$ to reduce as dissolved gas expansion increases and additional liquid is displaced. For the beryllium nozzle, we find $\min \left(C_{\text {phys }}\right) \approx 0.82 \pm 0.01$ under both degassed and dissolved $\mathrm{N}_{2}$ conditions. For the plastic nozzle, we find $\min \left(C_{\text {phys }}\right)=0.76 \pm 0.01$ under degassed conditions, and $\min \left(C_{\text {phys }}\right) \approx 0.73 \pm 0.01$ under dissolved $\mathrm{N}_{2}$ conditions. Even when additional gas expansion occurs in the exit region of the nozzle, the flow is still effectively choked at the vena contrata (see Fig. 9a), so there is no effect on discharge coefficient.

Analysis of the nozzle discharge coefficients from the pressure and mass flow rate data reveal that all the plastic nozzles and the beryllium nozzle follow a similar curve close to the solution of Nurick [35] for sharp-edged orifices. We compared several plastic nozzles with the same L/D and nominal diameter; polyetheretherketone (PEEK), Lexan polycarbonate, and Zelux, a medical grade radiation-hardened polycarbonate. All had $C_{D}$ values approx. 0.65 to 0.70 under strongly cavitating conditions, and $C_{D}$ values 0.80 to 0.85 under non-cavitating conditions, despite differences in small-scale geometric defects and their increased sensitivity to dissolved gas. This indicates that the presence of dissolved gas does not alter the discharge, but results only in a spatial rearrangement of the void distribution such that the velocity and contraction coefficients yield the same effective discharge. It is possible that nucleated gas, having a higher pressure than the vapor, displaces the voids previously occupied by cavitation; this is a matter of ongoing investigation.

\section{Conclusions}

In this paper, we have presented the results of x-ray radiography measurements of cavitation in a submerged beryllium nozzle. A novel aspect of this work is the ability to make quantitative measurements of the local vapor fraction, and by extension measure the contraction coefficient at any streamwise location in the nozzle. A gasoline surrogate with a cerium contrast agent was used as the working fluid. Time-averaged line of sight projections of the vapor volume fraction in the nozzle under cavitating conditions have been demonstrated at gasoline and diesel-like cavitation and Reynolds numbers. However, the nozzle diameter is approximately 2 to 3 times larger than a typical fuel injector, thus the operating pressure is correspondingly lower. Since cavitation bubbles do not scale with the nozzle diameter, the effects of this rescaling on the flow needs to be considered. However, recent x-ray measurements in rectangular channels have shown that the geometrically attached cavitation film tends to scale with the nozzle size [39]. It remains a matter for further investigation to determine whether the cavitation film in a round nozzle scales similarly. Beryllium nozzles are theoretically capable of operating over an extended temperature and pressure range, under more realistic engine-like conditions that cannot be reached with other materials, and they offer a long theoretical working life.

The vapor distribution in the nozzle had a projection profile indicative of an annular distribution, but it was slightly asymmetric. No clear evidence was found for large-scale (i.e. $>2 \mu \mathrm{m}$ ) asymmetry in the nozzle geometry, and we hypothesize that the flow asymmetry may be ascribed to microscale variations in the nozzle wall geometry and asymmetric separation of the flow from the wall.

Parametric investigation of the effects of cavitation number and Reynolds number on the vapor distribution revealed that the vapor distribution is highly sensitive to $K$ within a given range $(K=$ 1.01 to 1.57 for this nozzle). Below this range, the vapor distribution becomes insensitive to $\mathrm{K}$ and is effectively saturated. The vapor distribution was much less sensitive to Reynolds number in the measured range $\left(\operatorname{Re}_{D}=7000\right.$ to 35000$)$. Quantitative analysis of the area contraction caused by the expansion of vapor and gas revealed increased contraction with decreasing $\mathrm{K}$ and increasing $\mathrm{Re}_{D}$. Except for incipient 
conditions, the flow area did not recover immediately behind the vena contracta, as is often assumed in one-dimensional models. For the most strongly cavitating cases, the area contraction remained flat from the vena contracta to the nozzle exit, and supercavitation was measured in the outlet plenum. The increase in area contraction with $\operatorname{Re}_{D}$ implies that the exit area decreases as the flow rate increases, and this implies higher exit velocities than would otherwise be expected. Comparison of the physical area contraction coefficient near the exit plane and the discharge coefficient suggests that the velocity coefficients approach unity as $\mathrm{K}$ decreases and $\mathrm{Re}_{D}$ increases. Further work will be required to understand the effect of $\operatorname{Re}_{D}$ on nozzle exit conditions.

The effect of dissolved nitrogen on the vapor distribution in the nozzle was substantially reduced relative to that observed in polycarbonate nozzles. The presence of expanded gas did not alter the discharge or physical area contraction coefficient of the beryllium nozzle under any of the measured conditions. However, the plastic nozzle experienced a larger change in physical area contraction coefficient when dissolved gas was present. This suggests that in the absence of large-scale geometric defects, the gas displaces the cavitation voids, rather than creating additional liquid displacement. The current hypothesis is that much of the expanded gas in the polycarbonate nozzle is generated at pits and microcracks in the plastic wall, which are relatively absent in the beryllium nozzle. This has important implications for the validation of coupled non-condensable gas and cavitation models for fuel injection. However, more work needs to be done to investigate this matter.

The working fluid in this study was a gasoline calibration fluid with a relatively low vapor pressure compared to realistic fuels, and the experiments were conducted at room temperature. The use of more realistic geometries and higher vapor pressure gasoline surrogates at temperatures and pressures that more closely approximate engine-relevant fuel injection conditions will be a focus for future work.

\section{Acknowledgements}

This research was performed at the 7-BM beam line of the APS at Argonne National Laboratory. Use of the APS is supported by the U.S. Department of Energy (DOE) under Contract No. DE-AC0206CH11357. Argonne's x-ray fuel spray research is sponsored by the DOE Vehicle Technologies Program under the direction of Gurpreet Singh and Leo Breton.

Raul Payri was funded by a Fulbright visiting scholar grant in collaboration with the Ministry of Education, Culture and Sports of Spain (reference PRX14/00331) while performing this work. J.P. Viera was funded by the Spanish MINECO grant EEBB-I-15-0976 under project TRA2012-36932.

We gratefully acknowledge the computing resources provided on Fusion and Blues, computing clusters operated by the Laboratory Computing Resource Center at Argonne National Laboratory.

\section{References}

[1] Chaves H, Knapp M and Kubitzek A. Experimental study of cavitation in the nozzle hole of diesel injectors using transparent nozzles. SAE Technical Paper 1995; 950290: 199-211.

[2] Arcoumanis C and Gavaises M. Effect of fuel injection processes on the structure of diesel sprays. SAE transactions 1997; 970799 .

[3] Desantes JM, Payri R, Salvador FJ et al. Measurements of Spray Momentum for the Study of Cavitation in Diesel Injection Nozzles. SAE Technical Paper 2003; 2003-01-0703.

[4] Mitroglou N and Gavaises M. Mapping of cavitating flow regimes in injectors for medium-/heavyduty diesel engines. International Journal of Engine Research 2013; 14(6): 590-605.

[5] Gavaises M. Flow in valve covered orifice nozzles with cylindrical and tapered holes and link to cavitation erosion and engine exhaust emissions. International Journal of Engine Research 2008; 9: $435-447$.

[6] Schmidt DP and Corradini ML. The internal flow of diesel fuel injector nozzles: a review. International Journal of Engine Research 2001; 2(1): 1-22.

[7] Payri F, Payri R, Salvador FJ et al. A contribution to the understanding of cavitation effects in Diesel injector nozzles through a combined experimental and computational investigation. Computers and Fluids 2012; 58(C): 88-101. 
[8] Biçer B and Sou A. Application of the improved cavitation model to turbulent cavitating flow in fuel injector nozzle. Applied Mathematical Modeling 2015; 40: 4712-4726.

[9] Gavaises M, Villa F, Koukouvinis P et al. Visualisation and LES simulation of cavitation cloud formation and collapse in an axisymmetric geometry. International Journal of Multiphase Flow 2014; 68: 14-26.

[10] Battistoni M, Som S and Longman DE. Comparison of Mixture and Multifluid Models for In-Nozzle Cavitation Prediction. Journal of Engineering for Gas Turbines and Power 2014; 136(6): 061506.

[11] Koukouvinis P and Naseri H. Performance of turbulence and cavitation models in prediction of incipient and developed cavitation. International Journal of Engine Research 2016; in press. DOI: $10.1177 / 1468087416658604$.

[12] Arcoumanis C, Badami M and Flora H. Cavitation in real-size, multi-hole diesel injector nozzles. SAE transactions 2000; 2000-01-1249.

[13] Mitroglou N, Gavaises M and Arcoumanis C. Cavitation inside enlarged and real-size fully transparent injector nozzles and its effect on near nozzle spray formation. In Proceedings of the 2011 DIPSI Workshop. Bergamo, Italy.

[14] Payri R, Salvador FJ, Gimeno J et al. Study of cavitation phenomenon using different fuels in a transparent nozzle by hydraulic characterization and visualization. Experimental Thermal and Fluid Science 2013; 44: 235-244.

[15] Reid BA, Hargrave GK, Garner CP et al. An optical comparison of the cavitation characteristics of diesel and bio-diesel blends in a true-scale nozzle geometry. International Journal of Engine Research 2013; 14(6): 622-629.

[16] Payri R, Salvador FJ, Gimeno J et al. Study of cavitation phenomena based on a technique for visualizing bubbles in a liquid pressurized chamber. International Journal of Heat and Fluid Flow $2009 ; 30(4): 768-777$.

[17] Gavaises M. Cavitation inside multi-hole injectors for large diesel engines and its effect on the near-nozzle spray structure. SAE Technical Paper 2006; 2006-01-1114.

[18] Duke DJ, Kastengren AL, Tilocco F et al. X-ray Radiography Measurements of Cavitating Nozzle Flow. Atomization and Sprays 2013; 23(9): 841-860.

[19] Duke DJ, Schmidt DP, Neroorkar K et al. High-resolution large eddy simulations of cavitating gasoline-ethanol blends. International Journal of Engine Research 2013; 14(6): 578-589.

[20] Duke DJ, Swantek A, Kastengren A et al. Recent Developments in X-ray Diagnostics for Cavitation. SAE International Journal of Fuels and Lubricants 2015; 8(1): 135-146.

[21] Duke DJ, Swantek AB, Kastengren AL et al. X-ray Diagnostics for Cavitating Nozzle Flow. Journal of Physics: Conference Series 2015; 656: 012110-5.

[22] Bauer D, Chaves H and Arcoumanis C. Measurements of void fraction distribution in cavitating pipe flow using x-ray CT. Measurement Science and Technology 2012; 23(5): 055302.

[23] Mitroglou N, Lorenzi M, Santini M et al. Application of cone-beam micro-CT on high-speed Diesel flows and quantitative cavitation measurements. Journal of Physics: Conference Series 2015; 656: $012094-5$.

[24] Swantek AB, Kastengren AL, Duke DJ et al. Quantification of Shot-to-Shot Variation in Single Hole Diesel Injectors. SAE International Journal of Fuels and Lubricants 2015; 8(1): 160-166.

[25] Henke BL, Gullikson EM and Davis JC. X-ray interactions: photoabsorption, scattering, transmission, and reflection at $E=50-30000 \mathrm{eV}, Z=1-92$. Atomic Data and Nuclear Data Tables 1993; 54(2): $181-342$.

[26] Duke DJ, Swantek A, Tilocco Z et al. X-ray Imaging of Cavitation in Diesel Injectors. $S A E$ International Journal of Engines 2014; 7(2): 1003-1016. 
[27] Als-Nielsen J and McMorrow D. Elements of Modern X-ray Physics. 2 ed. Als-Nielsen/Elements, Hoboken, NJ, USA: John Wiley \& Sons, Inc., 2011.

[28] Lin KC, Carter C, Smith S et al. Investigation of Droplet Nucleation Inside A Beryllium Injector Using Small Angle X-Ray Scattering (SAXS) Technique. In Proceedings of the ILASS Americas 24th Annual Conference on Liquid Atomization and Spray Systems. San Antonio, TX.

[29] Andriotis A, Gavaises M and Arcoumanis C. Vortex flow and cavitation in diesel injector nozzles. Journal of Fluid Mechanics 2008; 610: 195-215.

[30] Soteriou C, Andrews R and Smith M. Direct Injection Diesel Sprays and the Effect of Cavitation and Hydraulic Flip on Atomization. SAE Technical Paper 1995; 950080.

[31] Strek P, Duke DJ, Swantek A et al. X-Ray Radiography and CFD Studies of the Spray G Injector. SAE Technical Paper 2016; 2016-01-0858.

[32] Duke DJ, Kastengren AL, Tilocco FZ et al. Synchrotron X-Ray Measurements of Cavitation . In Proceedings of the ILASS-Americas 25th Annual Conference on Liquid Atomization and Spray Systems. Pittsburgh, PA.

[33] Kastengren A, Powell CF, Arms D et al. The 7BM beamline at the APS: a facility for time-resolved fluid dynamics measurements. Journal of Synchrotron Radiation 2012; 19(4): 654-657.

[34] Duke DJ, Kastengren AL, Swantek AB et al. Time-Resolved X-ray Radiography of Cavitation in a Metal Nozzle. In Proc. ILASS-Europe 2016 27th Annual Conference on Liquid Atomization and Spray Systems. Brighton, UK.

[35] Nurick W. Orifice cavitation and its effect on spray mixing. Journal of Fluids Engineering 1976; 98: $681-687$.

[36] Battistoni M, Duke DJ, Swantek AB et al. Effects of Noncondensable Gas on Cavitating Nozzles. Atomization and Sprays 2015; 25(6): 453-483.

[37] Battino R, Rettich TR and Tominaga T. The Solubility of Nitrogen and Air in Liquids. Journal of Physical and Chemical Reference Data 1984; 13(2): 563-600.

[38] Hall GW. Analytical Determination of the Discharge Characteristics of Cylindrical-Tube Orifices. Journal of Mechanical Engineering Science 1963; 5(1): 91-97.

[39] Sou A, Minami S, Prasetya R et al. X-Ray Visualization of Cavitation in Nozzles with Various Sizes. In Proceedings of the 13th International Conference on Liquid Atomization and Spray Systems (ICLASS-2015). Tainan, Taiwan. 